\title{
AXEL HONNETH E A REFORMULAÇÃO DA IDEIA DO SOCIALISMO: DOS PROLETÁRIOS AOS CIDADÃOS
}

\section{LUIZ GUSTAVO DA CUNHA DE SOUZA ${ }^{1}$}

RESUMO: Em seu recente estudo sobre a ideia do socialismo, Axel Honneth dedica algumas páginas de sua exposição a um tema lateral em seu modelo de Teoria Crítica: a reflexão sobre os destinatários do discurso crítico. Na década de 1930, o espectro do proletariado como o destinatário da Teoria Crítica foi um elemento central para o desenvolvimento dessa tradição de pensamento por Max Horkheimer, ainda que este autor efetuasse importantes rupturas com a herança legada por Karl Marx. Para gerações posteriores de teóricos críticos, porém, a reflexão sobre o destinatário do discurso crítico pareceu perder importância, junto com as dúvidas quanto à possibilidade emancipatória representada pelo proletariado, de modo que a retomada do tema por Honneth oferece a possibilidade de lançar um novo olhar sobre o tema. A fim de fazê-lo, este artigo explora (I) a herança do pensamento de Marx para o estabelecimento dos destinatários da Teoria Crítica; (II) a forma como Horkheimer se apropria desta herança ao mesmo tempo em que procura romper com alguns de seus elementos centrais; a maneira como Honneth reapresenta a questão, (III) primeiro como um teoria das instituições e (IV) depois como uma teoria da democracia direcionada aos cidadãos de modo geral.

PALAVRAS-CHAVE: Axel Honneth; Teoria Crítica; Proletariado; Cidadãos.

ABSTRACT: In his recently published study on the idea of Socialism, Axel Honneth touches an apparently alien subject to his model of Critical Social Theory: the question about who are the addressees of the critical discourse. In the 1930's, although Max Horkheimer distanced his project of a Crtical Social Theory from the Marxist heritage of addressing the theory to the proletariat, this class still played a role in the former's model. However, for the following generations of Critical theorists, such a subject seemed unimportant, since their own models were exposed without reference to any particular social group. Hence, Honneth's interest on the subject allows one to take a new look at that old idea. In order to do so, this paper explores (I) the role the proletariat assumes in some works of Karl Marx; (II) how Horkheimer deals with the Marxist heritage and at the same time breaks away with any commitment with the proletariat and; how Honneth presents this problem first (III) from the viewpoint of a theory of institutions and then (IV) as a theory of democratic citizenship.

KEYWORDS: Axel Honneth; Critical Theory; Proletariat. 
As pessoas sabem com bastante clareza aquilo que não querem e aquilo que é revoltante nas atuais relações sociais; não possuem, no entanto, nem mesmo uma ideia parcial quanto à direção pela qual uma desejada mudança daquilo que existe deveria poder levar

Axel Honneth, Die Idee des Sozialismus

No texto em que formaliza o programa de uma Teoria Crítica da sociedade, Max Horkheimer define esse empreendimento como a dimensão intelectual do processo de emancipação do proletariado, estabelecendo claramente o aspecto primordialmente teórico da Teoria Crítica. Essa caracterização é oferecida em meio ao questionamento quanto ao potencial emancipatório do proletariado, já que, entre os elementos diagnósticos expostos pelo autor, encontra-se a admoestação de que a então situação presente da classe trabalhadora não inspirava ilusões quanto a seu potencial emancipatório. Esse elemento diagnóstico, a ruptura com a ideia de que uma teoria crítica da realidade social deva ser endereçada a um grupo específico dentro da realidade social é uma das principais divergências entre o projeto de Horkheimer e aquele que remonta à obra de Karl Marx que, na Crítica da Filosofia do direito de Hegel, atribuíra ao proletariado o papel de força prática da teoria. Essa ruptura, que estabelece uma certa autonomia epistemológica à Teoria Crítica da Escola de Frankfurt frente àquilo que Marx entendia como teoria crítica, se expressa por meio de uma questão central dentro do próprio desdobramento histórico da Escola de Frankfurt: a questão dos destinatários do discurso da Teoria Crítica.

Porém, mesmo que Horkheimer tenha exposto a desesperança no papel revolucionário do proletariado, seu trabalho ainda parte de um diálogo com a tradição de pensamento crítico para a qual esta classe poderia desempenhar uma atitude emancipatória; além disso, a arquitetura de seu projeto de Teoria Crítica esboçado no final da década de 1930 ainda é devedora das categorias analíticas da crítica da economia política. Assim, no momento de sua fundação, a Teoria Crítica vive uma tensão entre sua herança marxista e a ruptura com um dos elementos centrais desta tradição. A solução encontrada por Horkheimer, então, é afastar a tarefa de sistematizar o conteúdo da consciência proletária e, ao mesmo tempo, manter a tarefa de sistematicamente criticar a realidade social. Combinados estes dois elementos, não é 
difícil perceber que a Teoria Crítica, enquanto uma corrente específica de pensamento, nasce como um projeto sem sujeito oficial, de modo que à pergunta sobre a quem fala a Teoria Crítica a tentadora resposta inicial seria: a ninguém, pois trata-se exatamente disso, da crítica.

Esta atitude teórica parece ter sido legada por Horkheimer às gerações seguintes de teóricos que vieram a trabalhar na matriz frankfurtiana. No trabalho do principal autor da segunda geração da Teoria Crítica, Jürgen Habermas, essa ruptura com a herança marxista ganha um papel ainda maior. É justamente através da crítica à latência da categoria trabalho nos escritos de Adorno e Horkheimer sobre a totalidade social e a dominação racional, especialmente na Dialética do Esclarecimento, que se desenvolve a teoria normativa da comunicação. Todavia, também em Habermas, a ruptura com aspectos centrais do pensamento de seus predecessores é acompanhada pela manutenção da tarefa crítica, que ele associa à preservação dos espaços comunicativos e deliberativos livres de restrição. Assim, enquanto Horkheimer operara uma ruptura com a esperança revolucionária no proletariado mas preservara a ideia da crítica como um processo intelectual de emancipação frente à exploração diagnosticada pela crítica da economia política, Habermas rompe com a representação materialista do processo de emancipação mas preserva a associação da Teoria Crítica à manutenção ou estabelecimento de condições de emancipação. Assim como em Horkheimer, em Habermas a função crítica parece se dirigir antes à própria concepção de sociedade sobre a qual a Teoria Crítica se debruça: a tarefa da teoria é criticar aquilo que ela diagnostica e preservar, em uma dimensão intelectual, a possibilidade de conceituar a emancipação.

Porém, justamente esse caráter de uma teoria sem destinatário é o que motiva o mais importante autor da terceira geração da Escola de Frankfurt a, mais uma vez, propor uma reatualização dessa tradição. Axel Honneth critica o modelo de Habermas por seu caráter excessivamente abstrato e desancorado da realidade social, o que resulta em um tipo de teoria no qual não apenas relações de poder, mas também as próprias experiências de injustiça vivenciadas pelos sujeitos acabam ignoradas. Para Honneth, o ponto de apoio normativo de uma Teoria Crítica, dado o seu interesse emancipatório, não pode ser definido de modo abstrato, mas sim a partir das próprias demandas dos indivíduos envolvidos, de modo que é necessário à teoria existir uma instância categorial apta a captar as necessidades vitais e os interesses pré-teóricos dos indivíduos e, apenas a partir desta compreensão, construir seus motivos críticos. Honneth inicialmente estrutura seu próprio modelo de Teoria Crítica ao 
redor da categoria de reconhecimento, de modo a associar a situação empírica da Teoria Crítica ao interesse na luta pela formação de uma personalidade socialmente reconhecida, mas em seus escritos mais recentes também esse conceito de reconhecimento acaba recebendo um tratamento abstrato por se situar dentro do projeto mais amplo de reconstruir as bases institucionais da eticidade democrática moderna.

Naquilo que aparentemente representa uma mudança de rumo, todavia, Honneth, ao ser levado a defender seus escritos sobre a eticidade moderna da acusação de que estes representariam um reforço ideológico da sociedade existente, resolve fazê-lo por meio de uma tentativa de renovação da ideia do socialismo, isto é, de uma reformulação de sua base normativa. Ainda que um dos méritos de seu livro seja o de libertar a tradição do pensamento socialista de sua associação imediata ao marxismo, Honneth também faz concessões à tradição da revolução proletária ao encarar a questão sobre o destinatário do discurso do socialismo - e, por consequência, da Teoria Crítica - e, ao fazê-lo, formula também uma Teoria Crítica da democracia participativa.

O percurso esboçado acima é a principal inspiração deste artigo, mas não a única. $\mathrm{Na}$ verdade, este artigo procura responder de modo ligeiramente diferente de Josué Pereira da Silva à seguinte pergunta: a quem fala a Teoria Crítica? Para tanto, o artigo toma como pano de fundo sua tese de que o discurso da Teoria Crítica mudara seu ponto de referência do trabalhador para o cidadão. No entanto, ao contrário de Silva, aqui pretende-se afirmar que é apenas no trabalho mais recente de Honneth que esta mudança ocorre plenamente. Assim, o artigo procurará reconstruir alguns estágios da relação entre a Teoria Crítica e seus destinatários, iniciando (I) com sua pré-história na elaboração por Marx de uma teoria social crítica e passando (II) pela forma como Horkheimer formula uma Teoria Crítica da sociedade na qual subsiste uma tensão entre, por um lado, a herança marxista da interlocução entre teoria e grupos sociais e, por outro lado, a efetivação da crítica social. Finalmente, o artigo se dedicará à forma como Honneth, em primeiro lugar, (III) critica o desancoramento social da Teoria Crítica e, em segundo lugar, (IV) acaba por retomar a questão dos destinatários do discurso da Teoria Crítica por meio de uma solução afim àquilo que Silva sugerira anteriormente.

\section{Parte I - Marx e a ideia de uma teoria social crítica}


Naqueles anos do início da década de 1840 em que rompe com o sistema especulativo de Hegel, Marx divide seu tempo entre a continuação de seus estudos filosóficos e o trabalho formal como editor da Gazeta Renana, um jornal liberal editado em Colônia. Como editor desse jornal, ele é levado, por um lado, a travar conhecimento com recentes contribuições acadêmicas à economia política (uma disciplina que, no mais, já possuía espaço dentro da academia) e, por outro lado, a considerar o emergente movimento político socialista, duas temáticas que nunca mais deixariam sua obra.

Entre as atividades editorias dessa época se encontram seus escritos sobre a lei prussiana acerca do roubo de lenha, nos quais o jovem editor não escondeu seu desdém pelo modo como as classes proprietárias se apropriavam não apenas materialmente do território, mas principalmente deturpavam os professados princípios universalistas do Estado prussiano a favor de seus interesses particulares (Löwy, 2011, 17). Todavia, o proletariado aparece aqui apenas como uma classe cuja condição real é determinada exteriormente pela forma como as classes proprietárias se relacionam com o Estado. Ainda que isso signifique que, nesse momento, Marx não trata do proletariado como uma categoria filosófica, é justamente na crítica ao particularismo do Estado real que ele vem a descobrir categorialmente essa classe.

Afirmar que Marx descobre categorialmente o proletariado significa, de fato, que a partir de determinado momento de sua obra esta classe passa a ocupar um lugar específico na arquitetura geral de seu sistema teórico, isto é, no modo como Marx estruturalmente compreende a sociedade que está a analisar. A implicação dessa descoberta, como se verá mais tarde, não é outra senão o fato de que, a partir dela, Marx elabora um modelo particular de teoria social crítica, e um modelo que rompe com o padrão da filosofia social de sua época2. Por hora, porém, o que está em jogo é notar que a crítica de Marx ao sistema de filosofia política mais avançado de sua época, a filosofia hegeliana do Estado, inicia pela constatação de que a associação entre o Estado prussiano real e a filosofia racional parte de um lugar equivocado justamente por não considerar a existência do humano real. Esse é o tema central da Crítica da filosofia do direito de Hegel. Neste texto, Marx procura demonstrar como a escola hegeliana que associava o desenvolvimento real do Estado prussiano à filosofia racional nada mais fazia do que construir um anacronismo, uma vez que a história política alemã não passara pelos mesmos desdobramentos do que a história de outros países como a França e a Inglaterra (Marx, 1981, 379). Apesar disso, o Estado prussiano aparece à escola hegeliana do Estado racional como a realização de seus princípios filosóficos, o que leva 
Marx a afirmar que esta filosofia propicia aos alemães vivenciar sua pós-história (Marx, 1981, 383). O motivo para tal situação é a tentativa de associar uma realidade histórica e um sistema filosófico tomando como ponto de partida a possibilidade aberta pela reflexão, satisfazendo assim a realidade de uma maneira puramente imaginária e abstraindo o humano efetivo (Marx, 1981, 384-5). A exemplo da crítica da religião, porém, Marx afirma que na crítica política o humano há de ser tomado como produtor do mundo e não como um ser encolhido do lado de fora deste último. "O humano é o mundo do humano, o Estado, a sociedade" (Marx, 1981, 378), afirma ele, e na crítica religiosa esse mote serviu ao entendimento de que os humanos podem agir como senhores de sua razão sem remeter a imagens divinas. Quanto à crítica política, no entanto, a superação do caráter de limitada especulação filosófica demanda uma superação da própria crítica por meio de tarefas práticas (Marx, 1981, 385), isto é, tarefas que permitam superar as limitações práticas do Estado efetivo.

Nesse momento da obra de Marx, como fica claro, o ponto central dessas tarefas críticas não está relacionado com a superação do capitalismo ou com o estabelecimento de uma ordem social por uma classe, mas pela crítica do particularismo. Ocorre que essa crítica radical, assim como na crítica da religião, também deve tomar como sua raiz o próprio ser humano e suas relações sociais (Marx, 1981, 385). No entanto, o ser humano que leva a cabo a crítica radical das realidades política e filosófica precisa ser concebido sem impedimentos particularistas de um novo tipo. Esses novos particularismos ocorrem quando uma revolução é liderada por uma determinada classe que, partindo de sua condição particular, pretende libertar a sociedade. Nesse caso, a classe emancipa a sociedade, mas o faz sob seus próprios pressupostos - como na Revolução Francesa de 1789, quando sucessivas classes ocupam o poder clamando o papel de emancipadora universal (Marx, 1981, 390). Daí que a necessidade de uma revolução radical é a necessidade lógica de uma classe desprovida de interesses particularistas, ou seja, é preciso que essa classe não represente algo na sociedade civil, mas possua um caráter universal e que seu sofrimento seja igualmente universal, que a esta classe nada mais reste para ser reivindicado do que a própria humanidade que lhe é negada. Essas condições Marx encontra no proletariado (Marx, 1981, 390).

Ao contrário do que Marx e Engels escreveriam posteriormente no Manifesto do partido comunista, aqui a situação revolucionária do proletariado não se deve à sua condição de oprimido dentro das relações de produção e nem de qualquer implicação metafísica relativa ao conceito de trabalho. A descoberta categorial do proletariado como a única classe capaz de 
preencher os critérios que fazem com que a crítica radical da política alemã e a crítica radical da filosofia alemã se encontrem é devedora da necessidade de superar o particularismo que habita nestas duas.

Essa posição, segundo a qual o proletariado é o destinatário do discurso da crítica, logo seria incorporada em uma crítica da economia política, cujo primeiro esboço já apresenta uma mudança de ênfase: nos Manuscritos econômico-filosóficos de 1844 Marx afirma que, de acordo com os próprios pressupostos daquela ciência, o trabalhador se transforma em mera mercadoria e que a sociedade como um todo se reduz às classes trabalhadora e proprietária (Marx, 1968, 510). Essa concepção da sociedade como uma estrutura divida em duas classes antagonistas será radicalizada no Manifesto, escrito em 1848, quando Marx e Engels afirmam que, no processo de superação da organização social feudal, a nascente sociedade burguesa não só não suprimiu os antagonismos de classe - mas apenas lhes emprestou novas formas, substituindo as antigas classes, condições de opressão e de luta por novas -, como também simplificou os antigos existentes até então, uma vez que esta nova sociedade se caracteriza pela divisão gradual em dois grandes campos que se opõem, o da burguesia e o dos proletários (Marx e Engels, 1977, 463).

Ainda que em seus escritos históricos, como O 18 Brumário de Luis Bonaparte, Marx exponha uma visão mais nuançada acerca da estrutura de classes das sociedades burguesas, a noção de duas classes antagônicas é aquela que permanece central em seu pensamento e em sua crítica da economia política. Assim, n'O capital, particularmente no capítulo dedicado à transformação do dinheiro em capital, ele enfatiza que a relação entre a classe dos proprietários e a classe daqueles que possuem apenas sua força de trabalho é marcada pelo antagonismo de seus interesses a ponto de que, enquanto o capitalista busca na circulação do capital a valorização de seu capital inicial (Marx, 1962, 168), ao proletário que é obrigado a se submeter à relação comercial com o capitalista nada mais resta do que o curtume (Marx, 1962, 191). De fato, Marx entende as condições para a compra e venda da força de trabalho como o resultado de várias variações econômicas que levam ambos os lados a se encontrarem no mercado, mas para o capitalista, prossegue ele, estas condições pouco importam (Marx, 1962, 183), ou seja, a própria relação imediata entre as diferentes classes é concebida como uma relação de interesses antagônicos. De fato, essa descrição ecoa aquela do Manifesto, segundo a qual o desenvolvimento da classe operária depende do desenvolvimento do capital, 
pois aquela somente pode viver sob a condição de aumentar o capital (Marx e Engels, 1977, 468).

Uma tal concepção dos antagonismos de classe entre burguesia e proletariado não está plenamente desenvolvida nos escritos que Marx produz na primeira metade da década de 1840. Ali, a descoberta categorial do proletariado remonta a uma crítica do particularismo político e da parcialidade teórica. A este último ponto, que será central para o desenvolvimento da Teoria Crítica por Horkheimer, acompanha uma outra crítica, que também desempenhará um papel de destaque no trabalho de Horkheimer: a crítica de Marx à limitação das categorias analíticas da economia política. De acordo com Marx, o início da economia política (ou economia nacional) é o fato da propriedade privada. Todos os seus outros pressupostos decorrem desse primeiro, mas tanto estes quanto aquele são tomados como leis sem que suas causas sejam apontadas (Marx, 1968, 510). Daí que a parcialidade da economia nacional é similar àquela da filosofia política, pois ambas começam por abstrair de suas leis o mundo das relações sociais reais. O que Marx esboça nas páginas seguintes é sua teoria da alienação, mas para este artigo o que importa notar é que nestas páginas são expostas três determinações do trabalho estranhado (na relação do humano com seu produto, na relação do humano com relação a si mesmo e na relação do humano com sua espécie) que servem à demonstração de que, ao ignorar que da divisão do trabalho capitalista resulta uma apropriação do produto do trabalho por um ser estranho, a economia política falha em perceber que a propriedade privada, seu núcleo analítico, é consequência do estranhamento do trabalho (Marx, 1968, 519-20). Assim, a crítica da economia política é o movimento que revela a relação entre a economia baseada na propriedade privada e a desvalorização do humano.

Antes de prosseguir, há que se notar que através da descoberta categorial do proletariado e da consequente associação dessa descoberta a uma crítica das relações sociais realmente existentes, Marx reelabora um tipo de pensamento político associado à filosofia social. Nessa tradição, segundo Honneth, o ponto de partida para a análise se encontraria menos, como quer Hobbes, nas condições sociais que permitiriam a existência e reprodução do Estado do que, de acordo com Rousseau, nas causas para a degeneração desse Estado (Honneth, 2000, 13 e ss.). Esta última concepção encontraria posterior desenvolvimento na obra de Hegel, que compartilha com Rousseau a ideia de que desenvolvimentos patológicos das relações sociais levam ao perigo da limitação das condições da boa vida (Honneth, 2000, 
23), e nos Manuscritos que Marx redigiu em 1844 (Honneth, 2000, 26). No entanto, já nos Manuscritos, assim como antes na Crítica da filosofia do direito de Hegel, o trabalho de Marx parece ir além da filosofia social que se limita a teorizar as causas para a degeneração da vida social. É verdade que, como Honneth interpreta, a teoria da alienação representa uma análise de formas patológicas de sociabilidade, porém, a inclusão de uma teoria sobre as relações de classes e a forma como estas determinam as condições de existência dos membros dessas classes, bem como a própria organização da sociedade, ultrapassam o espectro de preocupações da filosofia social conforme concebido por Honneth. A esse novo tipo de preocupação com a organização da sociedade a partir da forma como os grupos que nela habitam se relacionam entre si, chama-se teoria social. No caso específico da teoria social fundada por Marx, todavia, os grupos sociais identificados pelo autor ao analisar a sociedade de seu tempo desempenham tanto um papel categorial quanto um papel político. Portanto, naqueles anos do começo da década de 1840, Marx empreende a descoberta da classe proletária como uma categoria central para a análise do capitalismo, mas também descobre que a economia política tradicional falha conceitualmente em entender a condição desta classe e o que ela revela sobre as limitações políticas efetivas da sociedade capitalista. Da junção dessas descobertas decorre, em primeiro lugar, a constatação de que a crítica radical é aquela que, tal qual a crítica da religião, agarra o problema pela raiz, que no caso dos seres humanos é a própria vida humana e sua organização; em segundo lugar, porém, a constatação de que a teoria só se tornaria uma força real quando agarrasse as massas (Marx, 1981, 385). Daí que, a partir da metade dos anos 1840, o sistema marxista se dirige, em grau mais ou menos explícito, às massas capazes de transformar a teoria em força real, fazendo delas o destinatário desse modelo de teoria social crítica.

\section{Parte II - Horkheimer e a formulação de uma Teoria Crítica da sociedade}

Marx manteve com o movimento proletário uma relação de apoio e esperança, por vezes permeada por críticas às suas estratégias políticas e teóricas, documentadas principalmente em seus estudos históricos. Mas mesmo nesses escritos nunca houve sinal de ruptura com aquela descoberta categorial realizada ainda na década de 1840, segundo a qual a teoria somente se tornaria força material quando agarrasse as massas. Pelo contrário: já desde os escritos de juventude, o proletariado aparece como a única classe capaz de superar o sistema capitalista porque é a única classe contra a qual se comete a injustiça por excelência, que é a perda total da humanidade (Marx, 1981, 390). 
Obviamente, tais pressupostos estão diretamente assentados sobre a experiência que Marx tivera ao observar as condições de vida da classe trabalhadora na Alemanha e na Inglaterra3. No entanto, também essa concepção do mundo como uma enorme coleção de mercadorias que, por não estar ao alcance daqueles que as produzem, fazem dos trabalhadores cada vez menores perde sua força na virada do século XIX para o século XX, quando a organização política dos trabalhadores começa a render as primeiras políticas trabalhistas e o proletariado já vivencia uma integração maior ao sistema capitalista (Jay, 1973, 43). Apesar disso, o modelo de uma teoria social crítica em nada havia perdido sua força quando Max Horkheimer e seus colaboradores no Institut für Sozialforschung (IfS) em Frankfurt am Main dão origem ao empreendimento que mais tarde seria chamado de Teoria Crítica da sociedade ou Escola de Frankfurt. Assim, Horkheimer afirma a respeito do proletariado que a dramaticidade de sua situação pouco se alterou: a estrutura da economia burguesa, diz ele, é tal que à riqueza produzida de um lado corresponde, necessariamente, do outro lado "uma impotência material e intelectual" (Horkheimer, 1975, 142). No entanto, isso não quer dizer que a situação existencial dessa classe sirva como confirmação de propósitos emancipatórios. Ao contrário da tendência à unificação do proletariado em torno da causa da eliminação de sua miséria causada pela exploração, Horkheimer afirma que na sociedade moderna, ainda que sofram as experiências da miséria e da injustiça, seus interesses imediatos não aparecem inevitavelmente como uma forma de superar a diferenciação entre classes (Horkheimer, 1975, 142-3). Dentro dessa sociedade, o princípio pelo qual se rege a economia é aquele segundo o qual os indivíduos se preocupam apenas consigo mesmos e, por isso, o mundo aparece à classe proletária, assim como a todas as outras, como um mundo estranho, no qual interesses pessoais e de classe são opostos. Isso faz com que os indivíduos reproduzam "uma realidade que os escraviza em medida crescente" (Horkheimer, 1975, 142). Devido a essa dificuldade estrutural para o desenvolvimento de uma atitude unificada do proletariado contra o sistema que aumenta a miséria de modo generalizado, "nesta sociedade tampouco a situação do proletariado constitui garantia para a gnose correta" (Horkheimer, 1975, 142).

Em primeiro lugar, então, é preciso notar que a preocupação de Horkheimer aponta para um deslocamento do papel categorial atribuído por Marx ao proletariado. Afinal, Marx baseava exatamente na condição do proletariado o seu papel emancipador, ao passo que Horkheimer não vê nesta condição uma garantia quanto ao direcionamento de uma teoria. Por isso, aliás, ele afirma que a mistificação das massas no pensamento de intelectuais com elas comprometidos resulta em cegueira e enfraquecimento das próprias massas (Horkheimer, 
1975, 143). Ao contrário de tal intelectual, Horkheimer advoga um tipo de pensamento que não respeite barreiras, mesmo quando este signifique se contrapor às massas. Para ele, trata-se de desenvolver um tipo de postura intelectual que não se limite a sistematizar conteúdos psíquicos de determinadas classes, pois esta sistematização tão somente revela as contradições entre uma dada ordem social e a classe que professa seus princípios como uma panaceia, mas não fornece uma imagem dos interesses emancipatórios que habitam a sociedade (Horkheimer, 1975, 143). Esse modo alternativo de pensar, livre de compromissos específicos com o proletariado, mas comprometido com o interesse na libertação, é visto por Horkheimer como "a face intelectual do processo histórico de emancipação do proletariado" (Horkheimer, 1975, 143). Ao pensamento baseado no interesse emancipatório e na experiência do sofrimento, Horkheimer chama de Teoria Crítica (Horkheimer, 1975, 138).

Ao efetuar uma mudança de ênfase com relação a como Marx tratava do proletariado, Horkheimer opera uma mudança dupla: por um lado, ao se distanciar do proletariado como guia da emancipação, ele altera o destinatário do discurso da sua teoria; mas por outro lado, ao estabelecer como nível de atuação da crítica a dimensão intelectual (em oposição ao comprometimento político), ele altera as próprias bases da teoria, abrindo assim a senda para um empreendimento filosófico particular. Para os propósitos deste artigo, é melhor começar o exame pelo segundo ponto, a formulação de uma Teoria Crítica em sentido específico.

Já nos escritos da década de 1840, absorvendo a herança da economia política, Marx tratara de investigar como a relação entre as diferentes classes sociais determinava o conjunto de relações de uma sociedade. Ao mesmo tempo, ele não abrira mão de denunciar em suas obras o fato de que esta era uma ordem injusta, na qual alguns indivíduos se valiam de sua condição para explorar outros indivíduos e, assim, gerar para si mesmos mais riqueza - e, consequentemente, mais miséria para os outros. Ao se interessar de modo crítico pela maneira como essas relações entre as classes organizam a sociedade, Marx rompera com a tradição clássica da filosofia social mas também com a economia política tradicional, colocando-se entre os primeiros autores a formular uma teoria social crítica. De modo ainda mais específico: o modelo marxista de teoria social crítica se baseia no desvelamento do caráter injusto da sociedade capitalista e resulta na formulação de uma crítica da economia política. No caso de Horkheimer, os pressupostos da crítica da economia política são explicitamente reconhecidos como o ponto de partida do pensamento crítico, pois são eles que colocam em suspeição as categorias do pensamento tradicional (Horkheimer, 1975, 138; 146). No entanto, 
a crítica da economia política ganha, para ele, os contornos de uma crítica epistemológica mais do que prático-política, dada a ruptura com a esperança na revolução proletária: na medida em que o comportamento crítico não é mais concebido como uma teoria que deseja se apoderar das massas e assim tornar-se uma força prática, o que lhe resta é exercer um tipo de pensamento que desvenda as condições para o surgimento de uma nova ordem (Horkheimer, 1975, 147). Para Martin Jay, isso significa que, devido às novas condições sociais, a Teoria Crítica de Horkheimer se diferencia do projeto anterior de uma crítica social porque esta poderia ser dita uma crítica imanente baseada na existência histórica de um sujeito, enquanto àquela resta a transcendência originada da dissolução da classe revolucionária (Jay, 1973, 43). Desse modo, Horkheimer, acompanhado por seus colegas do IfS, funda o empreendimento intelectual particular que seria associado à escola de Frankfurt.

Entretanto, esse empreendimento não apenas reconhece o valor da crítica da economia política como uma crítica social, mas também percebe que as condições sociais sob as quais a Teoria Crítica é realizada se diferenciam daquelas nas quais Marx e Engels se encontravam. O próprio desenvolvimento de fraturas de classe e de elites intelectuais faz com que alguns teóricos imaginem que o papel da teoria é o de oferecer uma visão mais completa sobre a sociedade, formando uma intelligentsia. Segundo Horkheimer, porém, tal posição se interessa por guiar os oprimidos à superação de sua miséria a partir de uma posição supra social, ao passo que à Teoria Crítica interessa superar a tensão entre indivíduo e sociedade (Horkheimer, 1975, 148). Aqui a fundação de um empreendimento intelectual específico se encontra, pois, com a outra mudança operada por Horkheimer, a ruptura com o destinatário de um sujeito para a Teoria Crítica.

Antes de afirmar a perda de confiança no proletariado, Horkheimer expusera, ainda como parte de sua crítica epistemológica à teoria tradicional, a ideia de que "o indivíduo aceita naturalmente como preestabelecidas as determinações básicas de sua existência" (Horkheimer, 1975, 138). A isso se soma o fato de que, devido à divisão do trabalho atual e às diferenças de classe, o todo social aparece à Teoria Crítica como cindido e contraditório, pois ao mesmo tempo em que os indivíduos reconhecem na organização social o resultado de suas atividades, também percebem que a sociedade que se organiza a partir da opressão não pode representar uma vontade autoconsciente e unitária, isto é, ela ainda é organizada externamente a partir de interesses do capital (Horkheimer, 1975, 138). Ao contrário de Marx, porém, que via na prevalência dos interesses do capital aos interesses gerais da humanidade um duplo 
processo de apropriação particular e de exploração, Horkheimer enfatiza o caráter de cisão do todo social que esse diagnóstico representa. Por isso, o lugar ocupado pela crítica da exploração na arquitetura da teoria de Marx é ocupado, na Teoria Crítica, por uma crítica abstrata da dominação generalizada, já que a atual organização social "é desumana, e essa desumanidade repercute sobre tudo o que ocorre na sociedade" (Horkheimer, 1975, 140, grifos meus). Essa mudança de ênfase frente à crítica da economia política, que apenas reflete o caráter epistemológico que Horkheimer atribui ao seu modelo, acaba adicionando um elemento à Teoria Crítica que reforça seu caráter autônomo dentro da tradição das teorias sociais críticas: como teoria do conhecimento, ela não possui um sujeito ao qual se dirigir, mas propõe um comportamento crítico. Daí a mudança mencionada por Jay, segundo a qual esta seria uma teoria transcendente.

A radicalização da crítica a outras formas de conhecimento, levada a cabo na Dialética do Esclarecimento, acaba por reforçar a ideia de que a Teoria Crítica se tornara um discurso sem destinatários, mas também origina a tentativa, realizada por Habermas, de corrigir a centralidade do paradigma do trabalho para a Teoria Crítica. Sua crítica se baseia no fato de que Horkheimer acaba por considerar que o processo de racionalização vivenciado pelo mundo ocidental faz com que os subsistemas sociais de ação racional se autonomizem frente aos impulsos éticos e moralmente fundamentados de seus membros, resultando em sociedades regidas puramente pela razão instrumental (Habermas, 1984, 353), que é justamente o tipo de racionalidade que, na Dialética do Esclarecimento, aparece como um desdobramento da forma de dominação da natureza cujo paradigma é a atividade do trabalho (cf. Habermas, 1984, cap. 4). No entanto, de acordo com Habermas, a centralidade desse paradigma no pensamento de Horkheimer (e de Adorno), expurga toda uma dimensão de interações intersubjetivas e comunicativas nas quais as formas assumidas pelos subsistemas de ação racional são legitimadas. A fim de incluir também essas interações dentro do modelo de uma Teoria Crítica, Habermas opera um deslocamento do paradigma do trabalho e procura reformular o modelo de crítica social a partir de uma divisão analítica que permita apreender tanto a dimensão comunicativa quanto a esfera da produção da vida material. Esse é o modelo bi-dimensional do sistema e do mundo da vida (cf. Habermas, 1987, cap. 6).

Entre os numerosos focos de interesse gerados pela estratégia reconstrutiva adotada por Habermas, este artigo irá se ocupar daquele que Josué Pereira da Silva identificou como uma mudança específica no destinatário da Teoria Crítica. Segundo ele, em uma interpretação 
ligeiramente diferente daquela de Jay, na mudança de paradigma operada por Habermas, da produção para a comunicação, o sujeito da Teoria Crítica passa a ser concebido de modo intersubjetivo, e não mais subjetivo, de modo que ao invés de dirigir-se para um grupo ou tipo de indivíduo específico, a Teoria Crítica passa a se dirigir a uma prática associada à cidadania (que Silva afirma ser pensada em sentido arendtiano, como um republicanismo dialógico). Daí a sugestão do autor de que na transição de Horkheimer para Habermas, "o discurso da Teoria Crítica está mudando de destinatário, está se transferindo do trabalhador para o cidadão" (Silva, 2008, 36). Nas próximas seções do artigo, pretende-se, a partir da análise de dois momentos da obra de Honneth, aprofundar essa sugestão de mudança, mas demonstrando que, se a princípio Honneth não seguiria o caminho identificado por Silva, em sua reconstrução da ideia normativa de socialismo essa tendência parece ter sido adotada.

\section{Parte III - Honneth: do reconhecimento às instituições}

A primeira contribuição de Honneth ao desenvolvimento da Teoria Crítica foi sua crítica ao unilateralismo de diferentes modelos dentro desta tradição. Assim, ele procurou demonstrar que, cada uma à sua respectiva maneira, as obras de Horkheimer, Adorno e Habermas supervalorizavam a dimensão da integração sistêmica ao custo da integração social4, o que as deixa cegas à dimensão da legitimação ética das normas e valores que organizam as sociedades capitalistas. Por isso, aliás, todos esses autores puderam expôr teorias da dominação em que um sistema de normas totalizantes se impõe sobre as interações individuais, seja como uma forma de domínio cultural ou como uma colonização dos imperativos sistêmicos sobre os valores éticos, por exemplo (Cf. Honneth, 1991, 29; 268). Apesar disso, Honneth afirma que a lógica comunicativa esposada por Habermas poderia orientar os esforços de reconstrução da Teoria Crítica, desde que sua lógica consensual fosse substituída por uma teoria da interação entre sujeitos sociais, de modo que o ponto de apoio da Teoria Crítica fossem as expectativas morais levantadas por esses sujeitos no momento de sua socialização (Honneth, 1991, xvii-xviii). O resultado seria uma Teoria Crítica que não se dirigiria nem a algum macrossujeito histórico, como o proletariado, nem à preservação de uma lógica abstrata, como a comunicação desimpedida; pelo contrário, atores sociais poderiam ser entendidos como grupos em busca da constituição de identidades sociais baseadas na conquista de reconhecimento a partir de sua interação com outros sujeitos (Honneth, 1991, 275). 
A partir da crítica à excessiva abstração do modelo de Habermas, então, Honneth procura desenvolver seu modelo de uma teoria da luta por reconhecimento, entendida não como uma mera demanda pela valorização da própria identidade, mas como um processo de interação mediado por um conflito entre expectativas quanto a esta personalidade. Desse modo, reconhecimento para ele significa um padrão de interação que corresponda aos valores éticos explicitados pelos sujeitos e que preencha suas expectativas no momento da socialização. Ao contrário do modelo habermasiano, Honneth enfatiza a dimensão da experiência do próprio sujeito em oposição à lógica por trás da interação, o que, de acordo com Silvio Camargo, lhe permite explicar as causas de conflitos sociais e a experiência de injustiça vivenciada pelos indivíduos (Camargo, 2011, 136). Porém, esta crítica ao caráter abstrato da teoria da ação comunicativa também indica que Honneth considera o modelo de Habermas desprovido de destinatários reais para a Teoria Crítica, algo que seu próprio modelo pretende corrigir ao endereçá-la aos grupos que interagem em busca de reconhecimento. Nesse sentido, a hipótese de que o modelo habermasiano marcaria um ponto de inflexão onde a Teoria Crítica mudaria o destinatário do seu discurso (Silva, 2008, 48) precisaria ser reformulada, pois mesmo este modelo se orientaria por uma imagem da cidadania como obtenção de consenso, e não como uma construção ativa a partir da experiência dos indivíduos. Dito de outra forma, a mudança do destinatário da Teoria Crítica não parece ser tão simples como Silva aponta, já que mesmo a ideia de cidadania passível de ser associada à teoria da ação comunicativa é mais abstrata do que prática, como, aliás, nota o próprio Silva $(2008,51)$. Daí que, seguindo a trilha aberta por Honneth, o destinatário da Teoria Crítica se encontraria antes em indivíduos capazes de ordenar eticamente suas expectativas quanto às normas de interação.

Contudo, também essa alternativa seria abandonada. Inicialmente, Honneth desenvolvera esse modelo interacionista da teoria do reconhecimento baseado em George Herbert Mead, para quem o desenvolvimento da personalidade individual depende da forma como as expectativas são cumpridas por um Outro externo que também altera suas expectativas a partir do momento em que entra em contato com o primeiro indivíduo, o que atribuiria à luta por reconhecimento um caráter não apenas intersubjetivo, mas propriamente conflitivo (Cf. Honneth, 2003[1994], cap. 3)5. Porém, em O direito da liberdade, Honneth adota uma posição mais complexa quanto à interação intersubjetiva. Por um lado, ele reconhece que a moralidade intersubjetiva do ideal comunicativo representa um avanço para a teoria social, porque é através dela que os sujeitos individuais puderam ser concebidos como 
membros autônomos que se encontram dentro de uma comunidade na qual sua autonomia é mediada pela presença de outros indivíduos com os quais a pessoa constrói valores e normas por meio da cooperação. A este processo, Honneth chama de uma dispersão do "Eu" no "Nós" (Honneth, 2011, 69). Por outro lado, Honneth afirma que a consciência da dispersão do "Eu" no "Nós" da comunidade, que é o princípio organizador da justiça nas sociedades modernas, somente pode ser alcançada quando são asseguradas ao indivíduo condições para a participação em instituições de reconhecimento recíproco, isto é, espaços nos quais a formação de um sujeito possa se autodeterminar como "Nós" (Honneth, 2011, 115). Esse contexto institucional no qual o reconhecimento recíproco não resulta da interação, mas de um princípio organizador das normas sociais, é o que Honneth chama de liberdade social.

Na medida em que nesse novo modelo a teoria da interação é substituída por uma teoria da intersubjetividade institucional, o destinatário da teoria mais uma vez parece mudar, já que as instituições é que são responsáveis por permitir o desenvolvimento das condições emancipatórias. Por isso, é tanto mais surpreendente que ao empreender a tentativa de reconstruir normativamente a ideia do socialismo, Honneth tenha dedicado atenção à questão sobre qual o destinatário desse discurso.

\section{Parte IV - Honneth: das instituições à cidadania?}

Na introdução a seu estudo sobre o socialismo, Honneth afirma que um dos motivos que o levaram a escrever esta peça foi responder às críticas ao seu estudo anterior, particularmente aquelas que apontavam que, ao enfatizar o pano de fundo normativo das instituições da modernidade, ele se afastara de qualquer intenção crítica à sociedade presente (Honneth, 2015, 12; Cf. Freyenhagen, 2015; Schaub, 2015). Para responder, Honneth inicialmente afirma que, ao mesmo tempo em que a indignação social nunca foi tão grande, sua falta de direção é uma das marcas de nossa época. Esse diagnóstico evidencia uma ruptura com toda a tradição crítica iniciada pela Revolução Francesa, segundo a qual todos os movimentos que se insurgiam contra o capitalismo eram acompanhados por uma imagem utópica (Honneth, 2015, 15), e leva à pergunta: Por que as visões do socialismo não mais convencem os concernidos de que a atual situação aparentemente imutável das relações sociais pode ser transformada para melhor através de esforços coletivos? (Honneth, 2015, 20).

A estratégia adotada por Honneth para responder a esta indagação é dupla: por um lado ele procura explorar as limitações que contribuíram para a perda de atração da utopia 
socialista; por outro lado, à luz da reconstrução e exposição dessas limitações, ele pretende apresentar uma série de possíveis reformulações conceituais que permitam a este ideal retomar seu potencial. Quanto ao primeiro desses passos, a crítica das limitações internas e externas da ideia do socialismo, Honneth identifica três complexos de problemas que contribuíram para sua derrocada, mas antes procura demonstrar que a crítica ao capitalismo expressa pelos primeiros socialistas, de Robert Owen a Henri de Saint-Simon, passando por Charles Fourier, não visava a implementação de um sistema de distribuição de bens mais justo, mas a de uma nova forma de vida comunitária na qual as condições de realização da liberdade individual se afastassem do puro individualismo capitalista, na medida em que considerava que os sujeitos só seriam livres enquanto membros de uma comunidade social que, por sua vez, somente poderia ser considerada livre quando a realização das intenções compartilhadas entre seus membros se baseasse antes em uma atitude de participação recíproca (Honneth, 2015, 53). Ou seja, de acordo com Honneth, o espírito do socialismo é muito menos o de uma sociedade livre de desigualdades econômicas do que o de uma sociedade na qual a solidariedade entre seus membros corrigiria a tendência capitalista ao egoísmo. Esse ideal, que se assemelha ao da liberdade social, foi desenvolvido pelo movimento socialista a partir de uma série de pressupostos que acentuaram seu "problema de nascença", segundo Honneth. Em primeiro lugar, todos compartilhavam a ideia de que a implementação de relações sociais solidárias dependia da superação do mercado capitalista; em segundo lugar, concordavam que nas relações sociais então existentes os motivos e condições para aquela derrubada já estavam presentes, já que trabalhadores, produtores e gerentes possuiriam um interesse unificado em uma economia organizada de modo cooperativo, de modo que o socialismo apenas representaria uma instância teórica de uma força preexistente na sociedade; em terceiro e último lugar, todos os representantes de primeira hora do movimento socialista se inclinam a uma visão de que a mudança social possui uma certa necessidade histórica (Honneth, 2015, 53). Ainda que essas três premissas do movimento socialista estivessem ligadas entre si de alguma forma, aquela cuja crítica possui maior relevância para a finalidade deste artigo é a segunda, isto é, a ideia de que o movimento socialista pressupunha que a força para a superação do capitalismo já se encontrava presente dentro da sociedade.

De acordo com Honneth, inicialmente nos escritos de Saint-Simon, mas posteriormente também em Owen, Louis Blanc e Pierre-Joseph Proudhon está presente, em diferentes formas, a ideia de que dentro da sociedade capitalista se encontra um grupo de 
pessoas que possuem um interesse compartilhado em que a sociedade desenvolva-se na direção de uma comunitarização de todos os produtores (Honneth, 2015, 65-6). Para Honneth, o problema não está em procurar dentro da realidade social as forças capazes de causar efeitos práticos que acompanhem a teoria, mas sim em identificá-las antes a partir dos interesses e desejos que esse grupo deveria possuir do que a partir de seus interesses empíricos (Honneth, 2015, 66). Ou seja, quando a atribuição de um destinatário à teoria não se dá a partir de uma investigação sociológica ou fática, resta apenas inverter a ordem desta teoria e colocá-la antes de seus sujeitos. Essa tendência tem sua representação mais marcante justamente nos trabalhos de juventude de Marx, nos quais o autor se dedica a uma antropologia filosófica da relação entre o produtor e seu interesse em ver sua atividade produtiva objetificada, interesse este que só pode ser representado pelo coletivo dos trabalhadores, uma vez que estes são os únicos atores sob o capitalismo que se dedicam ao trabalho objetivo e, por isso, experimentam o estranhamento de sua natureza. No entanto, prossegue Honneth, em seus escritos tardios Marx se afasta desta posição segundo a qual, como discutido na primeira seção deste artigo, o interesse dos proletários na libertação se deve à sua situação de nada possuir e poder tornar-se tudo: o interesse na revolução proletária se deve, n'O capital, à condição de exploração que leva aquela classe a lutar pela própria sobrevivência por meio da destruição deste sistema. Em ambos os casos, entretanto, Honneth afirma que Marx opera com a pressuposição de que, a despeito de toda diferença entre suas sensibilidades individuais, o sujeito coletivo representado pelo proletariado deve possuir um interesse unificado na revolução. O que isto resulta, para a doutrina socialista, é que a partir de então ela se viu ligada "por necessidade virtualmente transcendental à existência de um movimento social sobre o qual é empiricamente bastante obscuro até mesmo se, na realidade social, ele existe da forma prevista" (Honneth, 2015, 68). O que há de mais sério nessa associação, todavia, é que na ausência de um interesse pré-teórico, o socialismo perde também a justificação de sua existência, uma vez que sem a ligação a uma força social que possa efetivar seus objetivos, o socialismo passa a ser apenas uma teoria normativa qualquer (Honneth, 2015, 71).

Ora, a crítica de Honneth a este "problema de nascença" (Honneth, 2015, 54) do movimento socialista remonta à formulação da Teoria Crítica, particularmente à ruptura efetuada por Horkheimer quanto à crença no proletariado. No entanto, ao contrário deste último, Honneth acredita que a alternativa de um pensamento crítico ancorado em interesses internos à sociedade e suas diferenciações funcionais é mais atraente do que sua atualização como mera teoria normativa, pois a doutrina socialista (ou esse tipo de crítica ao capitalismo) 
é antes uma teoria reflexiva que objetiva novas formas de vida (Honneth, 2015, 86). Até este momento, deve estar claro que a lógica por meio da qual Honneth compreende a teoria socialista é idêntica àquela por meio da qual Horkheimer caracteriza a Teoria Crítica. Essa impressão se reforça ainda mais com a afirmação, feita por Honneth, de que a intenção da doutrina socialista é impulsionar forças sociais a tornarem a sociedade moderna efetivamente “social" (Honneth, 2015, 87), pois essa ideia ecoa aquela exposta por Horkheimer segundo a qual a Teoria Crítica deve contribuir para a superação de uma divisão do trabalho que separa os indivíduos de seu caráter social.

Apesar disso, a postura adotada por Honneth ao apostar na identificação de interesses críticos internos à vida social o coloca em oposição àquela transformação da Teoria Crítica em uma crítica transcendental; também o coloca em oposição à ampliação, identificada por Silva na obra de Habermas, do escopo da crítica para uma lógica abstrata. A versão rediviva da doutrina socialista apresentada por Honneth, afinal, se baseia tanto na crítica dos problemas de nascença dessa doutrina quanto em sua reformulação à luz da tarefa de encontrar as forças capazes de realizar a crítica interna da sociedade. E é quanto a este último ponto que Honneth, de modo inesperado, acaba por retomar o tema dos destinatários da Teoria Crítica - ainda que os chame de destinatários da doutrina socialista.

A fim de reformular aquela doutrina, Honneth afirma que a união de seus três problemas de nascimento deve ser superada, ou seja, além do apoio em um único movimento social, também a identificação entre capitalismo e mercado e o determinismo histórico que permeiam a obra de seus teóricos, devem ser deixados de lado. O ponto de partida para escapar a esta herança é encontrado por ele na noção de experimentalismo histórico, conforme exposta por John Dewey. De acordo com Honneth, a forma como Dewey se vale dessa noção o aproxima do núcleo da doutrina socialista, pois para este último o critério normativo para que se determine qual o modo mais amplo de responder a situações específicas que são vistas como problemas societários é a capacidade oferecida pela solução encontrada em afastar barreiras que impeçam a comunicação inteligente entre os membros da sociedade com o objetivo de resolver problemas. Ao estabelecimento de um contexto social que pretenda solucionar aqueles problemas identificados, Dewey chama, segundo Honneth, "experimentos" (Honneth, 2015, 97). Para Honneth, a vantagem de um tal procedimento experimental, que obviamente não é compatível com uma doutrina do determinismo histórico e da atribuição de um papel central a uma classe específica, reside no fato de que processos de mudança social 
não possuiriam um caráter pré-determinado pela lei histórica (Honneth, 2015, 96). No entanto, Honneth somente associa esse procedimento ao núcleo normativo da doutrina socialista após notar que Dewey também considera que o estabelecimento de uma comunicação mais amplamente livre de barreiras quanto possível é uma força crítica interna à sociedade, uma vez que, para o americano, qualquer grupo excluído "deve desenvolver um interesse elementar por sua inclusão em processos de comunicação da sociedade" (Honneth, 2015, 99). Nesse ponto, aliás, fica claro que, diferentemente de Habermas, que via no estabelecimento das condições de comunicação livre o interesse transcendental da Teoria Crítica, Honneth acredita que é no interesse pela participação em processos societários que se encontra o impulso para a resolução de problemas da vida coletiva; também é válido notar que, em uma aparente mudança de posição frente à sua exposição n'O direito da liberdade, aqui Honneth parece voltar a enfatizar o papel da interação social na construção de condições para o exercício da liberdade - ao invés de atribuir à institucionalização de formas intersubjetivas de reconhecimento recíproco esse papel.

Por meio dessa reformulação, prossegue Honneth, a doutrina socialista, por um lado, não mais seria vista como a consciência articulada da mudança social e, por outro lado, não mais seria entendida como um órgão reflexivo do grupo mais avançado dentro da luta de classes. Pelo contrário,

o socialismo deve ser entendido como a articulação especificamente moderna do fato de que no processo histórico novos e, de acordo com as condições da sociedade, variados grupos empreendem, ao demolir barreiras de comunicação e consequentemente tentar aumentar o escopo da liberdade social, esforços para fazer ouvir suas próprias reivindicações que, até o momento, não foram atendidas (Honneth, 2015, 104).

Nesse sentido, Honneth caracteriza o movimento socialista como a forma especificamente moderna da sempre presente tentativa de obter reconhecimento para as demandas ainda não aceitas publicamente, mas ele também caracteriza essa doutrina por seu escopo qualitativamente mais amplo do que em outros momentos históricos, uma vez que a exigência do "social" representa aqui um princípio estrutural da sociedade de acordo com o qual todos os impedimentos para uma prática da liberdade como uma reciprocidade solidária (solidarischer Füreinander) devem ser removidos (Honneth, 2015, 105). Como consequência desta reformulação, também a articulação desse núcleo normativo com as condições sociais deve ser reformulada, de modo que a esperança no proletariado - ou em qualquer movimento que em um dado momento histórico pareça encarnar uma ideia de emancipação - é substituída pela sugestão de que o progresso social se apresenta como uma ampliação das 
possibilidades de exercício da liberdade social (Honneth, 2015, 116). Nesse sentido, Honneth retoma a linha aberta em $O$ direito da liberdade ao afirmar que as demandas desse novo socialismo se deixam reconhecer antes nas conquistas institucionais da modernidade do que em coletivos que surgem, desaparecem ou alteram demandas em diferentes momentos históricos (Honneth, 2015, 118). Daí que, para Honneth, os destinatários do discurso desse socialismo reformado devem ser concebidos como os cidadãos capazes de perceber que sua liberdade individual somente é efetiva se se expressa sob a forma de interação solidária (Honneth, 2015, 118)6.

\section{Conclusão}

Em meio à sua tentativa de reformular a ideia do socialismo, Honneth acaba por retomar a questão dos destinatários da Teoria Crítica - ou da doutrina do socialismo, que ele associa à crítica do capitalismo - e confirma a hipótese levantada por Silva alguns anos antes, de que o discurso da Teoria Crítica se dirigia do proletário para o cidadão. Ainda que Silva tenha identificado esta passagem na obra de Habermas, é preciso lembrar que esse autor concebe o ideal comunicativo mais do que os efeitos da comunicação como central para a Teoria Crítica. No caso de Honneth, a ideia de participação nos processos de determinação da sociedade é que é central, de forma que a noção de cidadania que está por trás do direcionamento desse discurso da Teoria Crítica aos cidadãos parece menos abstrata do que a de Habermas e, além disso, parece submetê-la à condição de que o que deve ser objetivado pelo discurso crítico é a preservação de condições da liberdade social. Portanto, a tese de que o discurso da Teoria Crítica se altera em direção ao cidadão se prova correta, ao mesmo tempo em que os desenvolvimentos na própria Teoria Crítica - de Honneth, ao menos parecem apontar para o esboço de uma teoria das práticas democráticas levadas a cabo pelos destinatários do discurso crítico. Se essa teoria da interação experimental crítica é capaz de corrigir a ênfase dada por Honneth à institucionalização de espaços de liberdade é tema para uma discussão ainda mais profunda.

\section{NOTAS}

\footnotetext{
${ }^{1}$ Professor de Sociologia na Universidade Federal de Santa Catarina. Doutor em Sociologia pela Universidade Estadual de Campinas (Unicamp). E-mail: gustavo_cunha@yahoo.com.br.

2 Jacob Gorender considera que a obra tardia de Marx, centrada n'O capital representa uma unificação interdisciplinar das ciências humanas, dadas suas ramificações, a partir da economia política, em direção à sociologia, à historiografia, à demografia, à geografia econômica e à antropologia (Gorender, 2013, 46). A unificação destas disciplinas em um modo de fazer ciência social, porém, remonta já aos estudos de Marx da
} 
década de 1840, quando o autor se dedica a estudos econômicos, históricos, legais e antropológicos sem perder de vista a dimensão normativa de seu sistema.

3 Kenneth Tucker, por exemplo, nota que o sindicalismo francês do século XIX possuía muito em comum com aquilo que foi posteriormente teorizado como novos movimentos sociais e que seria orientado pela virtude republicana do igualitarismo democrático representado pelo ideal da participação, e não pela tendência revolucionária (Cf. Tucker, 1991, 88 e ss.)

4 Esta crítica à sobrevalorização da integração sistêmica frente à social continua presente em textos mais recentes de Honneth, como nota Emil Sobottka acerca da reformulação honnethiana da categoria analítica do trabalho (Sobottka, 2008).

5 Segundo Nancy Fraser, este modelo representa uma psicologização das lutas sociais, o que afastaria a teoria de uma crítica das relações sociais existentes ou mesmo do mal funcionamento das instituições sociais. Para ela, isso implicaria que o sujeito da crítica não seria o mundo social e seu objetivo não seria a mudança, mas problemas relacionados à psicologia individual (Fraser, 2001, 24). Entretanto, como apontam corretamente alguns autores, Fraser compreende o conceito de reconhecimento de modo equivocado (Saavedra e Sobottka, $2009,397)$ e ignora que os efeitos psicológicos de categorias políticas também são domínios da teoria da justiça (Pilapil, 2011, 94).

6 Como afirmei por diversas vezes ao longo do artigo, seu tema central é a retomada da discussão sobre os destinatários da Teoria Crítica - ou da doutrina da crítica ao capitalismo ou, ainda, do socialismo - no trabalho mais recente de Honneth. Por isso não irei tratar aqui das implicações que sua reformulação da ideia do socialismo geram para a relação entre Teoria Crítica e capitalismo, nem da sua teoria do mercado, ainda que considere ambas temas incontornáveis para que se entenda adequadamente seu trabalho.

\section{REFERÊNCIAS BIBLIOGRÁFICAS}

CAMARGO, S. Trabalho imaterial e produção cultural. A dialética do capitalismo tardio. São Paulo: Annablume, 2011.

FRASER, N. Recognition without ethics. In: Theory, culture \& society, 18, 2/3, 2001, 21-42.

FREYENHAGEN, F. Honneth on social pathologies: A critique. In: Critical horizons, 16, 2, 2015, 131-152.

GORENDER, J. Apresentação. In: MARX, K. O capital. Crítica da economia política. Livro I: O processo de produção do capital. São Paulo: Boitempo, 2013, 20-55.

HABERMAS, J. The theory of communicative action. Volume 1. Reason and the rationalization of society. Boston: Beacon press, 1984.

HABERMAS, J. The theory of communicative action. Volume 2. Lifeworld and system: A critique of functionalist reason. Boston: Beacon press, 1987.

HONNETH, A. The critique of power. Reflexive stages in a Critical social theory. Cambridge: The MIT press, 1991.

HONNETH, A. Pathologien des Sozialen. Tradition und Aktualität der Sozialphilosophie. In: HONNETH, A. Pathologien der Vernunft. Frankfurt am Main: Suhrkamp, 2000, 11-69.

HONNETH, A. Kampf um Anerkennung.Zur moralischen Grammatik sozialer Konflikte. Mit einem neuen Nachwort, Frankfurt am Main: Suhrkamp. Frankfurt am Main: Suhrkamp, 2003[1994].

HONNETH, A. Das Recht der Freiheit. Grundriß einer demokratischen Sittlichkeit. Berlin: Suhrkamp, 2011.

HONNETH, A. Die Idee des Sozialismus. Versuch einer Aktualisierung. Berlin: Suhrkamp, 2015.

HORKHEIMER, M. Teoria tradicional e Teoria Crítica. In: BENJAMIN, W., HORKHEIMER, M., ADORNO, T. W., HABERMAS, J. Textos escolhidos. São Paulo: Abril Cultural, 1975, 125-162. 
JAY, M. The dialectical imagination. A history of the Frankfurt school and the Institute for social research, 1923-1950. Heinemann: London, 1973.

LÖWY, M. Política. In: DUMÉNIL, G.; LÖWY, M; RENAULT, E. Ler Marx. São Paulo: Editora Unesp, 2011, 11-102.

MARX, K. Das Kapital. Kritik der politischen Ökonomie. Erster Band. Buch I: Der Produktionsprozess des Kapitals. In: MARX, K., ENGELS, F. Karl Marx und Friedrich Engels. Werke. Band 23. Berlin: Dietz Verlag, 1962.

MARX, K. Ökonomisch-politische Manuskripte aus dem Jahre 1844. In: MARX, K., ENGELS, F. Karl Marx und Friedrich Engels. Werke. Band 40. Berlin: Dietz Verlag, 1968, 465-590.

MARX, K. Kritik der Hegelschen Rechtsphilosophie. Einleitung. In: MARX, K., ENGELS, F. Karl Marx und Friedrich Engels. Werke. Band 1. Berlin: Dietz Verlag, 1981, 378-391.

MARX, K., ENGELS, F. Manifest der Kommunistischen Partei. In: MARX, K., ENGELS, F. Karl Marx und Friedrich Engels. Werke. Band 4. Berlin: Dietz Verlag, 1977, 459-493.

PILANPIL, R. Psychologization of injustice? On Axel Honneth's theory of recognitive justice. In: Ethical perspectives, 18, 1, 2011, 79-106.

SAAVEDRA, G. A., SOBOTTKA, E. A. Discursos filosóficos do reconhecimento. In: Civitas. Revista de ciências sociais, 9, 3, 2009, 386-401.

SCHAUB, J. Misdevelopments, pathologies and normative revolutions: Normative reconstruction as method of Critical Theory. Critical Horizons, 16, 2, 2015, 107-130.

SILVA, J. P. Trabalho, cidadania e reconhecimento. São Paulo: Annablume, 2008.

SOBOTTKA, E. O trabalho na discussão sobre bem-estar e desenvolvimento. $33^{\circ}$ Encontro annual da ANPOCS, 26 a 30 de Outubro de 2009, Caxambú.

SOBOTTKA, E; SAAVEDRA, G. A.

TUCKER, K. H. How new are the new social movements? In: Theory, culture \& society, vol. 8, n², May, 1991, 75-94. 